DOI: $10.1590 / 2316-4018376$

\title{
Tom, volume e arranjo no chiaroscuro da memória: Sinfonia em branco, de Adriana Lisboa

\author{
Regina R. Félix
}

To find a form that accommodates the mess, that is the task of the artist now.

Samuel Beckett

Uma micro-observação em movimento cronometrado, um ritmo, portanto, procura mimetizar a absorção dos personagens no momento reminiscente em que se encontram, e demarca, em Sinfonia em branco, a perspectiva poética da existência, espaçada oportunamente pelo mote "o tempo é imóvel, mas as criaturas (e os objetos, e as palavras) passam" (Lisboa, 2001, p. 24). Aquilo que tem um efeito de fluxo de consciência dos personagens é filtrado por um focalizador interno, através do qual aquele que vê e fala revela a reflexão e disposição de cada personagem dentro daquilo que Franz Stanzel denomina "situação narrativa figural", ou seja, através de uma voz reflexiva que pensa, sente e percebe, simulando a percepção de um registro diretamente transmitido sem mediações; quando "o narrador autorial é 'contaminado' pelo discurso dos personagens ficcionais", explica o autor (Stanzel, 1984, p. 192) ${ }^{1}$. O labirinto, estrutura que na mitologia grega propicia uma estetização do caráter tortuoso dos caminhos do inconsciente, é sugerido no texto como forma representativa do estar-no-mundo dos personagens Tomás, Maria Inês e Clarice de Sinfonia em branco. Assim marcando as chaves que os definem, a narrativa coordena seus caminhos e as formas como lidam com sua condição.

Sinfonia em branco leva o nome do quadro do pintor americano James Whistler (1834-1903), que intitulava seus trabalhos de modo a tornar clara a associação entre os conceitos da música e das artes visuais para alcançar sua forma não convencional de criar composições como arranjos de tons. Symphony in White, $n^{\circ}$ 1: The White Girl (1862) é o quadro ao qual a narrativa de Lisboa se refere (ver fig. 1); outro mote que se repete no texto o esclarece: "um branco virginal, uma moça vestida de branco que evocava um quadro de Whistler" (Lisboa, 2001, p. 9). Whistler provocou frisson com tal quadro, que para muitos sugeria o defloramento de uma virgem recém-casada. Ao usá-lo como referência, o livro Sinfonia em branco de Adriana Lisboa se vale dessas referências que acompanham o qua-

${ }^{1}$ A versão dos textos não disponíveis em português é de minha responsabilidade. 
Regina R. Félix

dro. Por um lado, explora os tons (musical, figurativo, retórico) no arranjo de brancos e sombras, por outro, a dimensão polivalente do que a moça do quadro transmite.

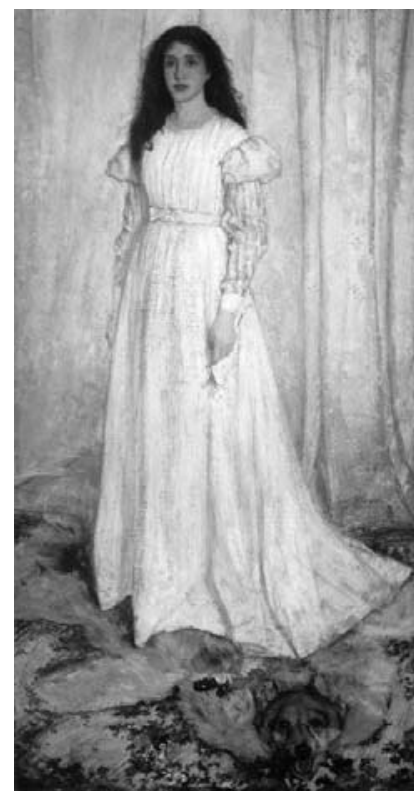

Fig. 1. Symphony in White, $n^{\circ} 1$ : The White Girl (1862), de James Whistler.

Neste trabalho, explicito o processo através do qual é entrelaçado o amadurecimento-como-reconfiguração-da-dor dos personagens Tomás, Maria Inês e Clarice, processo este que denota a convergência de elementos da música, da pintura, do cinema e, claro, da textualidade e de motifs literários. Por exemplo, volume se refere tanto ao espaço que aparições e ausências ocupam no texto, como à amplitude sonora das palavras em repetições, do mesmo modo como tons se relacionam às cores e às modulações que as disposições e vozes das personagem delineiam. $\mathrm{O}$ arranjo, orquestração, ou edição de textos e motifs coordenam os caminhos mentais labirínticos impostos pelo trauma. O claro-escuro/obscuro emerge no trabalho da memória que almeja elucidar aquilo que se apresenta como impenetrável aos personagens e se deixa abordar apenas através de configurações estéticas. 


\section{Volume: tons, aparições e silêncios}

A magnitude dos traumas de que Sinfonia em branco trata - a antecipação da infância e da juventude interrompida pela agressão e abandono dos adultos - mostra-se através do volume de vozes e aparições. $O$ halo cujo rastro mais marcante esboça o trauma é o dos silêncios e ausências, os "proibidos" (id., p. 17), mencionados amiúde. Estas são, em outras palavras, as regras passivamente conspiratórias que escondem as ferocidades praticadas em surdina. No texto, ausências e silêncios se expressam em oxímoros: a eloquente isenção rancorosa de Otacília (id., p. 36), a ruidosa quietude que invade a casa de Afonso Olímpio, cujo volume provoca também os ouvidos de Clarice (id., p. 206), e o excessivo vazio do qual Maria Inês insiste em evadir-se. Mas o trauma se configura também através de imagens que explicitam as cenas que lesionaram a imaginação dos três jovens. E embora se repita o mote "o tempo é imóvel, mas as criaturas passam" (id., p. 22), as marcas psicológicas do antes-de-tudo (id., p. 24) se imprimem em Clarice e Maria Inês, tanto quanto o antes-e-o-depoisde-Maria-Inês se gravam em Tomás (id., p. 168). Isto contradiz a noção do tempo que se perfaz exclusivamente na concretude dos movimentos humanos através do espaço, conforme o texto insiste em fazer crer. Ao contrário, o tempo vivido pelos personagens de Sinfonia em branco se mostra uma transição de estados existenciais, como sugere a durée de Henri Bergson, um processo qualitativo cuja experiência ocorre numa dimensão gradiente.

Tal dimensão é aquele processo de amadurecimento-como-reconfiguração-da-dor acima mencionado, cuja citação se desdobra no texto. Por exemplo, Clarice desvanece em cocaína e álcool, em pulsos cortados, tenta desfazer-se da cicatriz dos ataques sexuais do pai, como "segredos cauterizados" (id., p. 22), mas é em argila e mármore que vai dando forma ao "esquecimento profundo" (id., p. 76). Esquecimento do defeito familiar cuja visão, para Maria Inês, relampeja, nas incontáveis vezes em que, no texto, o delicado tesouro de cinco sementinhas de cipreste cai por terra, sinalizando o desmoronar do valor estético-simbólico de suas brincadeiras de irmãs e, portanto, o desmoronar da bela infância que nunca chegou a ser. Essas perdas se reiteram em cada pequena tentativa de aperfeiçoamentos brancos que o afortunado casamento de Maria Inês lhe oferece - "Sofá branco, paredes brancas, poltronas brancas. Ideias brancas e inverdades brancas. Muito mármore branco... Um infinito mundo asséptico de fantasia" (id., p. 19). É ela, a propósito, a garota de Whistler "que a memória vestia de branco e de juventude" (id., p. 100), ou seja, o branco 
Regina R. Félix

com que, de sua janela, Tomás substituiu a visão do abandono de seus pais - deixando o país, exilados (id., p. 28). Maria Inês preencheu aquele vazio de Tomás, de tal forma que ele, declaradamente, a ama como se a um ente da própria família.

Todos esses prismas da história que entrelaçam seus recalques são flashes que os personagens contemplam, às véperas de se encontrarem, depois de treze anos sem se ver. Contrapondo-se a essa sua prisão uns aos outros, perpassa o texto, como um motif, uma borboleta multicolorida que mergulha destemida, livre, exuberante, no abismo da pedreira cujo acesso fora sempre proibido às meninas, mas cujo perigo se confirma, em dado momento, com a queda mortal do pai. A borboleta, que representara a puberdade agredida de Clarice, rasga o texto como uma previsão bipartida entre conquista e temeridade; como audácia e promessa de cumprimento da punição ao agressor. Como tal, a borboleta, em oposição multicolorida à inefabilidade dos brancos, matura em seu casulo e desabrocha, tanto no empurrão que Maria Inês vinha planejando, como no assentimento silencioso de Clarice. Isso é o que sugere o focalizador desta última, após a queda do pai, quando especula sobre a possibilidade de justiça, concluindo, conforme sua candura usual, ao contrário de Maria Inês, que a vida não se submete a matemática alguma:

Como se chamava o inferno que vigia sobre a terra, à luz da razão dos homens? Nos corpos das moças violadas por seus próprios pais? Nos corpos torturados dos presos políticos? Nos corpinhos cheios de verminose e bernes e bichos-de-pé das crianças que trabalhavam a roça de sol a sol? A religião parecia querer tudo assim: como matemática. (id., p. 203)

Contrastando com a emoção crua de Clarice, porém, a matemática explicava o equilíbrio da adaptação conformada pela qual Tomás e Maria Inês optaram. Aquele, "nem feliz, nem infeliz" (id., p. 12), aceitara com a anonimidade a negação de seu talento artístico, esta, convivendo com os "assuntos murchos" do marido (id., p. 42), se refugia nos braços de amantes. Clarice, contudo, "dócil recatada submissa educada polida discreta. Adorável" (id., p. 192), abraça o absurdo no desequilíbrio.

Lidar com tais cenas que revolvem em sua mente os faz propensos a atentar àquilo que o focalizador de Maria Inês denomina "pequeninas desimportâncias" (id., p. 136). São exemplos disso as lembranças microescaneadas que acompanham a espera dos personagens, nas quais sua imaginação é invadida por detalhes que tomam conta de sua percepção. Estes, por um lado, sugerem o caráter inócuo de suas pegadas pelo mundo, enquanto também tecem a delicadeza estética da narrativa. Passagem 
alguma sintetiza melhor o entrelaçamento psicológico e estético da carga dramática que esse tipo de percepção transmite do que a que o focalizador de Maria Inês expressa quando da morte da mãe: "Do lado de fora de sua janela fechada, sementes vingavam e brotos cresciam ferozmente e borboletas multicoloridas morriam e eram carregadas por formigas" (id., p. 140). Ou seja, a observação de detalhes diminutos se expande numa atenção que testemunha a funda cicatriz em sua consciência, que encalha, por assim dizer, em certos detalhes, absorta em absoluta interiorização, o que, por sua vez, vale repetir, expressa-se apenas em figurações estéticas.

\section{Arranjo: composição da ordem existencial}

O que Adriana Lisboa faz em Sinfonia em branco se assemelha ao que Virginia Woolf comenta sobre seu The Waves (1931) - "minha dificuldade é que escrevo para um ritmo e não para um enredo" (Parsons, 2000, p. v). Em Sinfonia em branco, também uma cadência se mostra na repetição dos temas acima citados, que ganham realce com parlendas ("hoje é domingo, do pé de cachimbo, o cachimbo é de barro..." (sic) (Lisboa, 2001, p. 44), travalínguas ("O rato e a roupa do rei de Roma" (sic) (id., p. 44) e outras referências ao folclore infantil. Através delas, representa-se, em geral, o trauma como cantilena repetitiva, típica das cantigas da infância, em que os personagens ainda habitam. Mas tais referências também indicam sentidos específicos. Um exemplo é a mimetização da ambiguidade da relação com o marido em suas aventuras bissexuais, apontada por Maria Inês ao recitar mentalmente a parlenda "um homem alto-baixo, gordo-magro sentado-em pé..." (id., p. 44). Também o travalínguas "Três tristes tigres" (id., p. 44) sugere os vários triângulos amorosos: entre o pai, a mãe e Clarice; entre esta, Maria Inês e Tomás, entre os pais de Tomás e ele mesmo, entre o marido de Maria Inês, esta e os amantes de cada um, e assim por diante. Finalmente, como se para duplicar outra presença fantasmagórica que se repete no texto, qual seja, a do "monstro que devora infâncias. Será uma ilusão de ótica?" (id., p. 53), emprestam-se os olhos matreiros do lobo mau às reminiscência de Maria Inês: "pensou em Chapeuzinho Vermelho, para que esses olhos tão grandes, vovozinha? Para enxergar palavras que não são ditas" (id., p. 48).

Esses são artifícios cuja repetitividade marca métrica e sentido próprios bem como se apresentam como um dispositivo narrativo, algo que conota um fluxo emotivo por associação, que transmite a compulsão de recorrer a imagens marcantes como uma forma de compreendê-las. Sigmund Freud o sugere quando fala do incansável desejo infantil pela re- 
Regina R. Félix

petição que se encontra em pacientes traumatizados: “Está claro que em suas brincadeiras as crianças repetem tudo aquilo que lhes causou uma grande impressão na vida real, e deste modo elas soltam a força da impressão e, por assim dizer, se fazem mestres da situação" (Freud, 1961, p. 16). Tratando da discursividade intrínseca ao trauma, Cathy Carruth explica a repetição no seu cerne como "a atuação repetida e não intencional de um evento o qual não se consegue deixar para trás" (Carruth, 1996, p. 2). A autora nota que a dor mental permanece como trauma porque o evento que o provoca acontece repentina e inesperadamente demais, a ponto de não poder ser compreendido, sendo, portanto, "não disponível à consciência até que se imponha outra vez, repetidamente, nos pesadelos e ações repetitivas do sobrevivente" - e assim aquele que sofreu o impacto continua preso à imagem que o abalou (id., p. 3-4).

Através de sua história entrelaçada pelos meandros de cortes algo cinematográficos, o processo conjunto dos personagens em reminiscências solitárias, em Sinfonia em branco, se demonstra um trabalho que executa o que Clifford Wulfman observa sobre a tarefa do escritor modernista, quando fala da escrita de Woolf - algo como tentar mimetizar o processo de percepção não sequencial, bem como o traçado dessa percepção que procura tornar-se compreensão (Wulfman, 2007, p. 159). Um traçado se expressa na reflexão de Clarice: "sentia-se enfim como tendo cumprido alguma espécie de trajeto. De percurso. Acabou por se dar conta de que havia lentamente sobrevivido..." (Lisboa, 2001, p. 217) quando, enfim, deixa de lado a busca pelo esquecimento.

O percurso existencial do livro de Lisboa, ademais, dialoga de perto com ideias-chave de $O$ Mito de Sísifo de Albert Camus. O trauma do incesto, sofrido por Clarice e testemunhado por Maria Inês, e os abandonos sofridos por Tomás precipitam o desnudamento de seu mundo habitual, repleto das expectativas típicas da vida comum, desvelando o mundo como um lugar irreconhecível ou inóspito. A perspectiva posterior ao acontecimento, que se mostra como uma espécie de voice over em relação à cena que descreve, nos dá essa dimensão do trauma como estranhamento do mundo:

A mãe delas estava em casa costurando. O pai delas havia ido até a cidade comprar uns remédios. Ainda eram apenas isso, naquela época: mãe, pai. Amigos potenciais ... Ainda não havia medo, ainda não havia monstros respirando pelos cantos da casa: somente o futuro - que brilhava de expectativas como brilhavam os olhos delas. (id., p. 220)

Essa passagem nos comunica o potencial de tudo o que o trauma impe- 
diu e nisso se assemelha ao que nota Camus, ou seja, o sentido do absurdo que emerge quando há uma cisão do ser com seu ambiente, tornando-o estranho diante de sua própria vida. Ao mesmo tempo esse desnudamento suscita a estetização daquilo que veio antes do trauma e daquilo que $o$ mundo poderia ter sido não fora o trauma. O trauma, portanto, se desvestiu, a expectativa das meninas possibilita seu revestimento através das imagens que compõem o texto. É o que mostra a absorção, acima citada, dos personagens em sua observação expandida, granulada em detalhes, daquilo que está ao seu redor, mostrado em câmera lenta. Nas palavras de Camus, essa observação in close up faz com que o mundo nos escape como o pano de fundo costumeiro que ele é da aventura humana e se torne um enfoque engrandecido - "esta densidade e estranheza do mundo é o absurdo" (Camus, 1983, p. 14).

Esse mal-estar-no-mundo, chamado de "náusea" por Jean-Paul Sartre, e que também é mencionado por Camus, aparece também aqui: "uma criança de nove anos de idade. Uma porta entreaberta. A náusea, o medo" (Lisboa, 2001, p. 40), bem como a confirmação da matemática existencial por Maria Inês e sua negação por Clarice, como já foi apontado. Camus ironiza a matemática na acepção que chama de "acrobacias da lógica" ou o "apetite pela clareza", responsável pela antropomorfização do mundo que tenta driblar a "cruel matemática" do tempo que nos aproxima da morte (Camus, 1983, p. 16-7). Maria Inês, inadequada mas racional, acredita na vitória da verdade (Lisboa, 2001, p. 219), enquanto a suicida Clarice, "dócil, recatada, submissa, educada, polida, discreta. Adorável" (id., p. 192), tendo sentido o absurdo sobre a pele, sabe que "as vidas e os sentimentos que norteiam (...) não são matemática" (id., p. 203).

O que os livros de Lisboa e Camus têm em comum é que tratam de uma situação na qual há um rompimento no próprio tecido social. Se para Camus foi a Segunda Grande Guerra a perspectiva-limite a provocar a dúvida quanto à viabilidade da vida, no livro de Lisboa, é a quebra do laço entre pai e filha que o faz. Em outras palavras, o contato com uma irracionalidade radical e inexorável é o que configura o absurdo, num rompimento que permite acesso ao mundo nu e a uma visão que atravessa convenções e provoca a descrença em valores éticos. É aqui que essa experiência psicológica se transforma no claro-escuro estético com que, acredito, o texto trabalha: de um lado, a crença nas promessas civilizacionais e, de outro, o prevenir-se contra a iminente animalidade humana. 
Regina R. Félix

\section{Claro-escuro: Dionísio e Apolo}

Os tons, cores e vozes dos três pesonagens nos passam um Tomás pintando Maria Inês de branco (drawing a blank), num flash com o qual apaga da memória o exílio dos pais, ele, que de fato vive no "mundo marrom e ressecado e empoeirado" da fazenda (Lisboa, 2001, p. 9). Maria Inês se revela nos brancos e azuis (os mármores brancos, o céu "azul não confiável" do Rio de Janeiro, a gelée corporal azul, enfim, água e ar), através dos quais procura corrigir imperfeições. Clarice, a mais frágil e a que menos se focaliza internamente na narrativa, é a mais visceral dos três. A pouca mediação de sua experiência pelo texto mimetiza sua imanência, esculpida em argila e mármore. Junta terra e água/ar, como se em si perfizesse a combinação de Tomás e Maria Inês.

Vemos, então, o claro-escuro que perpassa Sinfonia em branco, desde a oposição mais óbvia entre o elemento Terra de Tomás e Clarice, de um lado, e de outro, a Água e o Ar com os quais Maria Inês é ilustrada. Também, nesse sentido, as meninas são distinguidas, sendo Clarice a mais morena, apesar do nome, e Maria Inês a mais pálida (id., p. 30). A ambivalência claro-escuro que estrutura Sinfonia em branco é, ademais, insinuada pelo livro Morte em Veneza de Thomas Mann, mencionado repetidamente, evidenciando-se como um outro motif. A menção da novela se faz pano de fundo, não apenas para as escapadas bissexuais do marido de Maria Inês, mas, mais revelador, para a dualidade e contraposição entre Dionísio (caos) e Apolo (ordem). Veneza, o cenário da novela de Mann o suscita, como explica Terence Reed: "Veneza não é um cenário aleatório, mas um encontro sagaz entre a tradicional origem indiana do deus Dionísio e uma cultura ocidental que se recusa a reconhecê-lo" - lembremos que o protagonista de Mann é um devoto de Apolo que se deixa inflamar por uma paixão dionisíaca (Reed, 1994, p. 11-2).

O vocábulo sinfonia do título de Adriana Lisboa, por sua vez, suscita a ideia de resolução para as contraposições que compõem o livro. É também musicalmente sugestiva a maneira como se apresentam as existências não menos malogradas dos coadjuvantes do trauma, ecoando como um coro trágico na cena de fundo: a mãe frustrada de Clarice e Maria Inês, Lina, a amiguinha estuprada e morta, os pais exilados de Tomás, a solitária e subserviente tia-avó Berenice das meninas, o eco, provindo da Fazenda dos Ipês, do marido linchado por ter esfaqueado a mulher adúltera, a institucionalizada e abandonada sogra de Maria Inês e sua própria dor ao se dar conta dos casos amorosos do marido. A sinfonia encadeia, quase cenograficamente, falas e imagens, elementos da música e da pintura 
como confluência das artes, única via possível para a transmissão da sincronia dos personagens no trauma. Organiza os traços de um Tomás que compreende o lado desordenado da existência, a "sinuosidade da vida" (Lisboa, 2001, p. 158), tanto quanto Clarice, que, pouco antes da tentativa de suicídio, se encontra num labirinto "sem o fio de Ariadne" (id., p. 183). A referência à linha de Ariadne, a propósito, se faz pensar no labirinto criado pelo artífice Dédalus para aprisionar o minotauro, como conta o mito grego, também sugere a necessidade de uma solução lógica para os dilemas dos personagens que a sinfonia em livro, de Lisboa, então, congrega. Através de suas vozes, a resolução se configura segundo as fórmulas do romance e da sifonia. Uma observação evocativa de John Pemble chama a atenção àquilo que a sinfonia como forma artística respondia no seu auge: "a estrutura sinfônica resolveu o caos e o conflito como ordem e harmonia. A sinfonia de Beethoven revelou o rerum concordia discors (a concórdia dissonante das coisas) e transcendeu a paixão humana em abstração pura" - como forma artística que no século XIX procura aplacar as contradições da época (Pemble, 1995, p. 5).

Tal abstração (compositora, por assim dizer) se perfaz no ponto-devista do focalizador de Maria Inês, que se sobressai entre os outros por sua voz crítica, sendo ela, aliás, aquela à qual a narrativa se refere como "competente contadora de histórias" (Lisboa, 2001, p. 16). Sua voz, no final do livro, depois de declarar o "inventário de si mesma", aventa uma elucidação algo epifânica, mas abstrata, lógica - uma solução depois da espera na escuridão dos recalques, que constitui todo o livro até então: "Na verdade, não há anos passados ou anos futuros a contabilizar. E nada de novo... Não obstante, tudo é novo. Fiat lux." (id., p. 218-9). Para Clarice e Tomás, por outro lado, o enigma de Maria Inês a triangular sua relação decifra-se no encontro concreto entre os dois: "segura a cabeça dele com as duas mãos, como se fosse uma escultura... Agora Tomás segura levemente (...) os seios dela com as duas mãos, como se fossem uma escultura", demonstrando, mais uma vez, o esculpir de suas circunstâncias com as próprias mãos (id., p. 215). O claro-escuro, como na relação memóriaelucidação, aparece como mais um recurso para transmitir a tarefa da compreensão do incompreensível. Como sugere o tenebroso de Michelangelo Caravaggio, nas palavras de Rudolf Wittcower, na nuance também delineada em Sinfonia em branco, em "formas sólidas e impenetráveis ... lançadas em semi-escuridão ... uma luz forte cai sobre elas, modela-as e dá a elas uma qualidade tridimensional robusta", ou seja, o trabalho de aclarar e conferir luminosidade àquilo que, deste modo, se imbui de um significado vigoroso para o entendimento (Wittcower, 2001, p. 24). 
Regina R. Félix

O claro-escuro, expõe, em luz e sombra, o modo como a memória arrisca consigo mesma no processo de tornar inteligível aquilo que se guarda como inacessível, tabu, e se deixa abordar apenas através das configurações estéticas, engenhosamente definida como uma sinfonia em branco. Por um lado o escuro, o caos dionisíaco, representado na infância interrompida de Clarice e Tomás. Por outro, o testemunho de Maria Inês como a menina de branco de Whistler. Para Tomás, uma jovem não convencional, cabelos em desalinho, que leva na mão um lírio, algo imaculado, enquanto pisa sobre um tapete feito de pele de urso. Para Clarice, este gesto, um emblema do domínio da menina sobre forças ferozes e dificilmente domesticáveis - da menina que matou o pai, o monstro que devorava infâncias ${ }^{2}$. Assim, Sinfonia em branco encadeia dissonâncias e as reintegra como aquilo tudo de inefável que finalmente consegue processar-se; como tenebrosos sons do esquecimento que brancos tentam iluminar.

\section{Referências bibliográficas}

CAMUS, Albert (1983). The Myth of Sisyphus. New York: Random House.

CARRUTH, Cathy (1996). Unclaimed Experience. Trauma, Narrative and History. Baltimore: John Hopkins University Press.

FREUD, Sigmund (1961). Beyond the Pleasure Principle. New York: W.W. Norton and Company.

FORD, Jane (1998). Patriarchy and Incest from Shakespeare to Joyce. Gainesville: University Press of Florida.

LISBOA, Adriana (2001). Sinfonia em branco. Rio de Janeiro: Rocco.

PARSONS, Deborah (2000). "Introduction". Waves. Virginia Woolf. Ware: Wordsworth Editions.

PEMBLE, John (1995). Venice Rediscovered. Oxford Clarendon Press.

PETERS, Lisa (1996). James McNeill Whistler. New York: Todtri Publishers.

REED, T. J. (1994). Making and Unmaking of a Master. New York: Twayne Publishers.

SARTRE, Jean Paul (1964). Nausea. New York: New Directions Publishing Corp.

STANZEL, Frank (1984). A Theory of Narrative. New York: Cambridge University Press.

\footnotetext{
${ }^{2}$ Lisa N. Peters interpreta o quadro pré-raphaelita de Whistler, exibido no Salon des Refusés em 1863, como colocando lado a lado a pureza do lírio branco e a rudeza da pele de urso sob os pés da menina. Para Peters, isso "reflete a perda da inocência de uma jovem mulher", pois o símbolo da inocência feminina contrasta com a força masculina que a imagem do tapete comunica (Peters, 1996, p. 16).
} 
WITTCOWER, Rudolf (2001). "Art and Architecture in Italy 1600-1750 I". Early Baroque. 6. ed. revisada por Joseph Connors and Jennifer Montagu. Yale: Yale University Press.

WULFMAN, Clifford (2007). "Woolf and the Discourse of Trauma: The Little Language of the Waves". In: HENCE, Suzette e ELBERLY, David (Orgs). Virginia Woolf and Trauma. New York: Pace University Press.

Recebido em setembro de 2010.

Aprovado para publicação em novembro de 2010.

\section{resumolabstract}

Tom, volume e arranjo no chiaroscuro da memória: Sinfonia em branco, de Adriana Lisboa

Regina R. Félix

Este trabalho mostra o paralelo entre o processo psicológico dos personagens Tomás, Maria Inês e Clarice e as formas musical, plástica, cinematográfica, literária, pelas quais expressam seu esclarecimento gradativo ao lidar com seus traumas. Tom, volume e arranjo se fundem. Configuram-se como aparições e ausências, em sombras e luzes, em vozes que modulam silêncios e protestos. As memórias desconexas e repetitivas dos personagens se orquestram segundo aqueles padrões estéticos como tentativa de desvendar o absurdo de sua situação.

Palavras-chave: literatura e outras artes, literatura e trauma, literatura e existencialismo/absurdo, memória e estética, Adriana Lisboa

Tone, volume and arrangement in the chiaroscuro of memory: Sinfonia em branco, by Adriana Lisboa

Regina R. Félix

This article shows the parallel between the psychological process of the characters Tomás, Maria Inês and Clarice and the musical, plastic, cinematographic, and literary forms through which they express their gradual awareness in dealing with their traumas. Tone, volume, and arrangement merge with each other. They are configured as appearance and absence, in shadow and light, and in voices that modulate silences and protests. The characters' memories, disconnected and repetitive, are orchestrated according those aesthetic patterns as an attempt to unravel the absurdity of their situation.

Key words: literature and other arts, literature and trauma literature and existentialism/absurd, memory and aesthetics, Adriana Lisboa

Regina R. Félix - “Tom, volume e arranjo no chiaroscuro da memória: Sinfonia em branco, de Adriana Lisboa". Estudos de Literatura Brasileira Contemporânea, n. 37. Brasília, janeiro-junho de 2011, p. 93-103. 